\title{
Analysis and Comparison of Impacts of Design Optimization Approaches with Occupant Behavior on Energy Consumption Reduction in Residential Buildings
}

\author{
Mahmoud Shakouri Hassanabadi, Saeed Banihashemi, and Amin Rasouli Javaheri
}

\begin{abstract}
The high-energy demand in residential buildings, which is also growing rapidly, necessitates a better understanding of its major influencing factors and developing a methodology for reducing energy consumption. Among various factors influencing residential building energy consumption, occupant behavior and design optimization play essential roles in the energy performance. This paper aims at drawing an analogy between the results of design optimization vis-a-vis improving users profile in terms of reduction in energy consumption. A double story bungalow located in Johor Bahru which has a hot tropical climate was used as a case study and required cooling load was calculated by using Ecotectect analysis software. Results of this study showed that structural modifications can save up to $33 \%$ of energy loss while, proper usage can reduce the loss up to $71 \%$ in cooling load. It was concluded that the conscious of tenants in using electric devices and consuming energy is much of higher importance than providing sustainable features in the house.
\end{abstract}

Index Terms-Design optimization, energy performance, occupant behavior, cooling load.

\section{INTRODUCTION}

Currently, energy consumption in residential buildings forms a large part of the total national energy consumption (TNEC) in both developed and developing countries [1]. For example, in the US and Japan, residential building energy consumption accounts for $25 \%$ and $26 \%$ of TNEC respectively [2]. In Malaysia, commercial and residential buildings use about $13 \%$ of total energy consumption and $48 \%$ of electricity consumption [3]. The high energy demand in residential buildings, which is also growing rapidly, necessitates a better understanding of its major influence factors. At the same time, it is necessary to develop a methodology for reducing energy consumption [1]. It is known that any attempt to improve the energy performance of buildings should go through a systematic scenario.

At the building level, when the envelope parameters are designed with the purpose of optimizing the energy performance, the size and capacity of mechanical equipment can be reduced and, consequently, the electrical power distribution system may also be reduced. However, the optimum design of the building envelope will not necessary lead to an exemplary high energy performance due to the fact that the energy consumption is strongly influenced by the

Manuscript received March 9, 2012; revised September 20, 2012.

The authors are with the Department of Construction Management at Universiti Teknologi Malaysia (e-mail: shmahmoud3@live.utm.my, sbnseyed2@live.utm.my, javaheri_amin@yahoo.com). building's system and occupants. The quest for optimum energy performance requires a coherent application of parameters which together optimize the performance of the whole building's systems. It is therefore necessary to apply an integrated approach to the process of optimizing building design and evaluating performance [4]. In general, the factor influencing the total building energy performance can be divided into seven categories:

1) Climate (e.g., outdoor air temperature, solar radiation, wind velocity, etc.),

2) Building-related characteristics (e.g., type, area, orientation, etc.)

3) User-related characteristics, except for social and economic factors (e.g., user presence, etc.),

4) Building services systems and operation (e.g., space cooling/ heating, hot water supplying, etc.),

5) Building occupants' behavior and activities,

6) Social and economic factors (e.g., degree of education, energy cost, etc.), and

7) Indoor environmental quality required [5].

Among various factors influencing residential building energy consumption, occupant behavior and design optimization play essential roles in the energy performance and are difficult to investigate solely due to their complicated characteristics [1]. With the growth in construction activities, it has become imperative that design tools to be provided, can give insights into the sustainability of a building at an early design stage itself, and helps the design team incorporate the sustainable solutions in a building very early in the design process.

This paper aims at drawing an analogy between the results of design optimization and improving users profile in terms of reduction in energy consumption. It is difficult to completely identify the influences of occupant behavior and activities through simulation due to users' behavior diversity and complexity; current simulation tools can only imitate behavior patterns in a rigid way [5]. In this paper, the occupant behavior is defined by setting the thermostat range and altering hours of operation.

\section{RESEARCH METHODOLOGY}

The case study is a double story bungalow located in Johor Bahru. It was modeled in Revit Architecture and exported to Autodesk Ecotect Analysis for energy analysis. The second story of the building is not for living purposes and only provides day lighting for the level below. Since this building is constructed through industrialized building 
system (IBS), the plan is symmetric and has a modular format. The length of the panels is $3.3 \mathrm{~m}$ with the same amount of height. Fig. 1 shows the layout of the building. Each unit in this building has two bedrooms in which one of them has access to day lighting and the other one has an indirect access to natural light through the void.

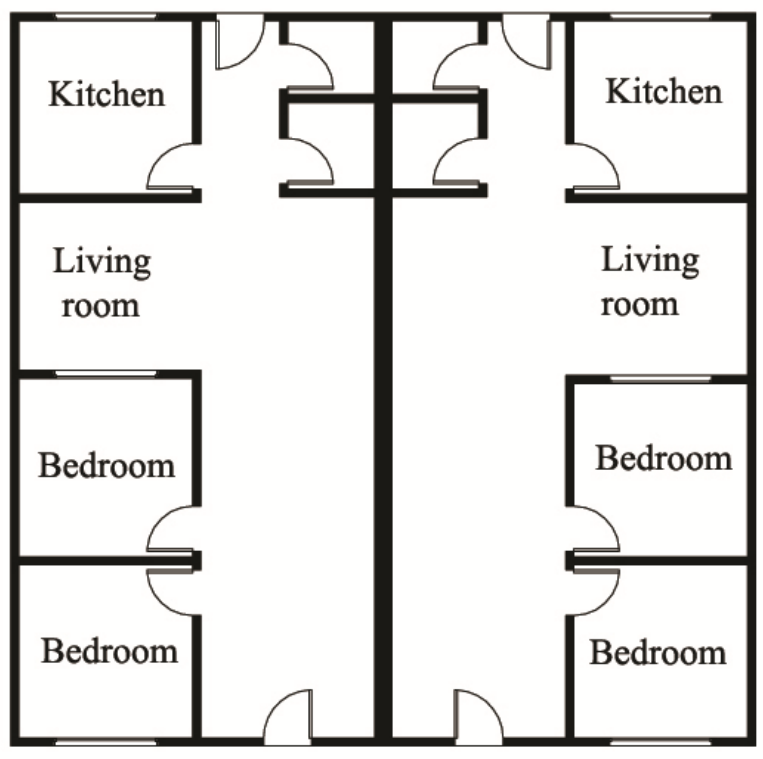

Fig. 1. Plan layout.

As for the base simulation of the model, homogeneous precast concrete panels were used for walls, which have the $\mathrm{U}$ value of 1.49. Metal deck roof with a layer of glass fiber as insulation and ceramic tile as the cover of the roof with the total $U$ value of 0.61 was used for the roof of the model and single gazed window with aluminum frame with the $U$ value of 6 was chosen as the typical materials used in buildings in Malaysia.

Johor Bahru is the second largest province of Malaysia and is located on 3.1o Latitude and 101.6o longitude. It has a tropical climate which means that throughout the year, there is not a severe fluctuation in the temperature. Since the daily temperature varies between 22 oC - 33 oC constantly and Malaysia never experiences cold days of winter, the loads that the designer should consider while designing for air conditioning systems are only cooling loads.

For simulation, each room in the building was defined as a zone and each zone had its own thermal properties. It was assumed that the residents use mechanical cooling systems for cooling bed rooms and living room and natural ventilation for the rest of the zones. The thermostat was set between 18-26 oC to provide comfort level for the occupants. The result of simulation is given in Table I.

\begin{tabular}{lrrr}
\multicolumn{4}{c}{ TABLE I: COOLING LOAD OBTAINED FROM SIMULATION. } \\
\hline Orientation & Heating & Cooling & Total Loads \\
\hline $0^{\circ}$ & 0 & 29467237 & 29,467 \\
\hline
\end{tabular}

\section{ANALYSIS AND DISCUSSION}

The analysis of zonal specifications reveals that according to Table II, cooling the bedrooms with the total volume of $143.76 \mathrm{~m} 3$ constitutes $34 \%$ of the total cooling load. This figure compared to the cooling load of the living room which its volume is about 3 times more, is significant. This is due to the reason that from the western and eastern walls of 4 bedrooms, two bedrooms are exposed to the sunlight which increases the heat gain of the rooms and consequently increases the cooling load of the bedrooms. Owing to the depth of the shade on the level above, the south part of the building is never under the direct sunlight, which is considered as an advantage for the tropical climate of Malaysia.

TABLE II: ZONAL SPECIFICATION.

\begin{tabular}{ccccc}
\hline Name & Perimeter $(\mathrm{m})$ & Area $\left(\mathrm{m}^{2}\right)$ & $\begin{array}{c}\text { Volume } \\
\left(\mathrm{m}^{3}\right)\end{array}$ & $\begin{array}{c}\text { Cooling Load } \\
(\mathrm{kWh})\end{array}$ \\
\hline Kitchen 1 & 13.2 & 11 & 35.94 & $\mathrm{Na}$ \\
Kitchen 2 & 13.2 & 11 & 35.94 & $\mathrm{Na}$ \\
Living room 1 & 40.8 & 50 & 173.22 & 6,034 \\
Living room 2 & 40.8 & 50 & 173.22 & 6,189 \\
Toilet 1 & 6.1 & 2 & 7.62 & $\mathrm{Na}$ \\
Toilet 2 & 6.1 & 2 & 7.62 & $\mathrm{Na}$ \\
Bath 1 & 6.8 & 3 & 9.64 & $\mathrm{Na}$ \\
Bath 2 & 6.8 & 3 & 9.64 & $\mathrm{Na}$ \\
Bed room1 & 13.2 & 11 & 35.94 & 2,208 \\
Bed room2 & 13.2 & 11 & 35.94 & 2,856 \\
Bed room3 & 13.2 & 11 & 35.94 & 2,159 \\
Bed room4 & 13.2 & 11 & 35.94 & 2,832 \\
Void 1 & 13.2 & 11 & 35.94 & 3,540 \\
Void 2 & 13.2 & 11 & 35.94 & 3,645 \\
\hline
\end{tabular}

This scenario is worse for the case of the voids on the second floor. With only accounting for $12 \%$ of volume of the air-conditioned zones, this zone consumes $24 \%$ of cooling load. This is again due to the conduction, convection, direct and diffuse solar radiation that occur in those zones which consequently increases the heat gain in this zone from all four sides.

It can be inferred that voids provide a significant portion of loads in the building. The voids do not have any occupancy role in the building and just provide day lighting for the level below. As a result, the volume of the voids is the key in optimizing the building performance. To improve the design, it was suggested that to reduce the cooling load, the height of the void be reduced and to increase the day lighting, the dimensions of the glazing in the voids be increased. Figs. 2-3 show the changes of dimensions applied to the base model.

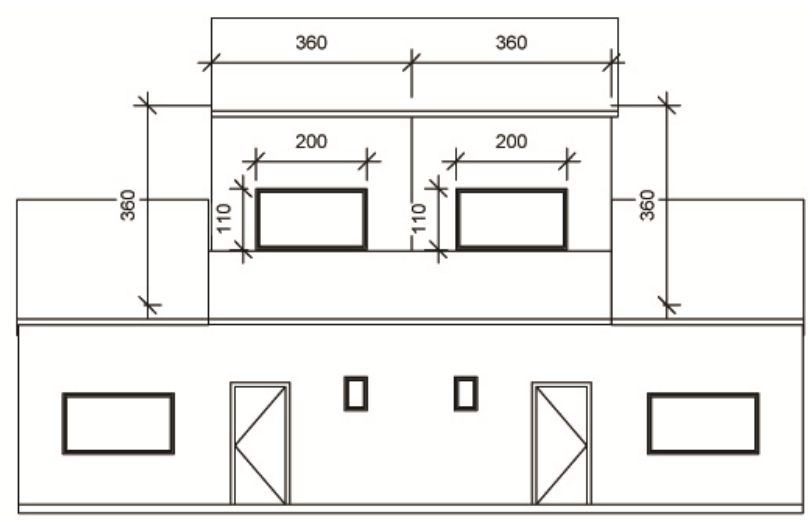

Fig. 2. South elevation of the based model. 


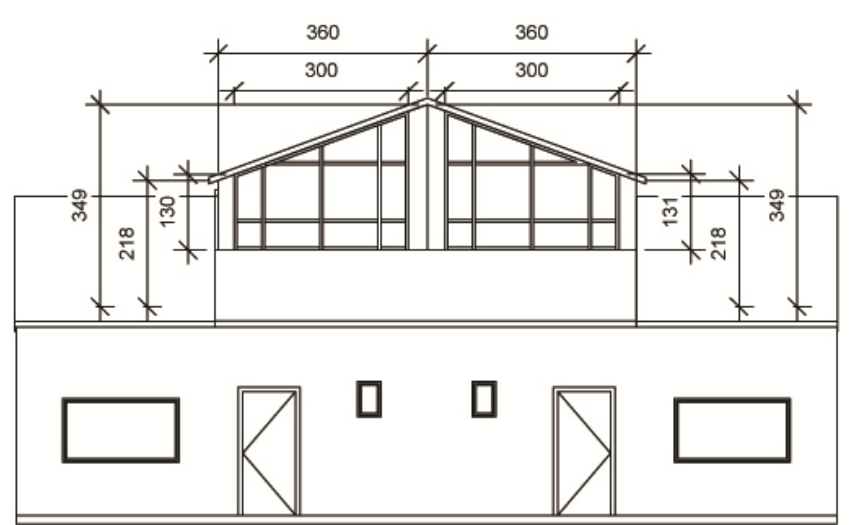

Fig. 3. South elevation of the modified model.

According to these changes, the volume of the each void has decreased from $35.94 \mathrm{~m} 3$ to $34.18 \mathrm{~m} 3$ and the area of the glazing in each void has increased from $2.2 \mathrm{~m} 2$ to $5.55 \mathrm{~m} 2$. Based on these changes, the total load of the modified model decreased to 26,411 $\mathrm{kWh}$ which is a significant value.

This means that by reducing the volume of the void by $2 \%$, we can reduce the cooling load of the building by $10 \%$. On the other hand, the increased area of the glazing in the void provides more light and improves the indoor quality of the building as well (Table III).

TABLE III: COMPARISON RESULTS OF MODIFICATION.

\begin{tabular}{ccccc}
\hline & $\begin{array}{c}\text { Based } \\
\text { Model }\end{array}$ & $\begin{array}{c}\text { Modified } \\
\text { Model }\end{array}$ & Reduction \% & $\begin{array}{c}\text { Amount } \\
\text { reduction }\end{array}$ \\
\hline $\begin{array}{c}\text { Void } \\
\text { Volume } \\
\text { Glazing } \\
\text { area }\end{array}$ & $35.94 \mathrm{~m}^{3}$ & $34.18 \mathrm{~m}^{3}$ & & \\
Total Load & $2.2 \mathrm{~m}^{2}$ & $5.55 \mathrm{~m}^{2}$ & 10 & $3,055 \mathrm{kWh}$ \\
& $\begin{array}{c}29,467 \\
\mathrm{kWh}\end{array}$ & $26,411 \mathrm{kWh}$ & & \\
\hline
\end{tabular}

Management of hours of operation of HVAC is a crucial key in saving energy. The zones must be cooled or heated only when they are occupied. Apart from the physical properties of building zones, number of occupants, types of activity and the thermostat range all contribute to the amount of heating or cooling load. The based simulation in this study was designed for the worst scenario in which all the systems work nonstop throughout the year. This means that for instance, during the day that people may not use the bedrooms, they are kept in the comfort level which is not necessary. The same story applies for the living room. By proper management of operation hours, one can save a considerable amount of energy and cost.

Hence, as for the operation management, two scenarios will be introduced here that in one of them, the operation time will be dependent on the occupancy of the zone and in the other, the thermostat range will be changed to meet the minimum comfort level for the occupants. All the changes are applied on the base model and no design change is implemented here. In the first scenario for bedrooms and living rooms, two different operation schedules were defined.

\begin{tabular}{ccccc}
\multicolumn{4}{c}{ TABLE IV: NEW OPERATIONAL HOURS OF HVAC } \\
\hline Zone & Weekdays & Weekends & $\begin{array}{c}\text { Thermostat } \\
\text { Range }\end{array}$ & $\begin{array}{c}\text { Total } \\
(\mathrm{kwh})\end{array}$ \\
\hline Living room & $18: 00-00: 00$ & $12: 00-24: 00$ & $18 \mathrm{C}-26{ }^{\circ} \mathrm{C}$ & \\
Bed room & $22: 00-8: 00$ & $0: 00-12: 00$ & $18 \mathrm{C}-26{ }^{\circ} \mathrm{C}$ & 8,315 \\
\hline
\end{tabular}

It was assumed that people use the bedrooms only for resting and spend other times in the living room. For the weekends, it was assumed that people stay longer in their beds and as a result, the operational hours are longer compared to the weekdays. Based on the given timetable, a new simulation was run and the result shows a significant decrease in the cooling load of the building. Table IV shows that by implementing the given schedule, the amount of total loads compared to the base model, will decrease about $71 \%$. This equals to 21,150 $\mathrm{kWh}$ which is very significant.

ASHRAE defines thermal comfort as the state of mind in humans that expresses satisfaction with the surrounding environment. The thermal comfort differs from person to person but generally, it is defined between 18 oC to 26 oC. To test the impacts of thermostat range on the cooling, the values shown in Table $\mathrm{V}$ were used for the zones.

TABLE V: THERMOSTAT RANGE VARIATION AND ITS EFFECTS ON TOTAL LOADS.

\begin{tabular}{ccc}
\hline Zone & Thermostat Range & Total $(\mathrm{kWh})$ \\
\hline Hall & $18 \mathrm{C}-25 \mathrm{C}$ & 12,900 \\
Bed room & $18 \mathrm{C}-25 \mathrm{C}$ & \\
Hall & $18 \mathrm{C}-22 \mathrm{C}$ & 18,867 \\
Bed room & $20 \mathrm{C}-25 \mathrm{C}$ & \\
\hline
\end{tabular}

The results show that reducing only 1 oC from 26 oC to 25 oC results in 4,585 kWh increase in the total loads. Along the same line, if two different thermostat ranges are defined for the zones as given in Table $\mathrm{V}$, the increase would be significant. This suggests that low ranges of temperature for the thermostat would have an inverse impact on the total loads. In other words, for maintaining lower temperature in the house, larger cooling load is required and vice versa.

\section{CONCLUSION}

Because Although proper construction and detailing is a crucial factor in achieving an energy efficient building, but the method of operation and utilizing the services cannot be underrated.

Results of this study show that structural modifications can save up to $33 \%$ of energy loss while proper usage can reduce the loss up to $71 \%$ in cooling load. In some sustainability assessment tools, extra marks are given for tenant appraisal which makes sense here. A green building is green if it is used in a green way. The conscious of tenants in using electric devices and consuming energy is much of higher importance than providing sustainable features in the house.

\section{REFERENCES}

[1] Z. Yu, F. Haghighat, C. M. Fung, E. Morofsky, and H. Yoshino, “A methodology for identifying and improving occupant behavior in residential buildings,” J. Energy, vol. 36, pp. 6596-6608, 2011.

[2] L. G. Swan and V. I. Ugursal, "Modeling of end-use energy consumption in the residential sector: a review of modeling techniques,” J. Renewable and Sustainable Energy Reviews, vol. 13, pp. 1819-35, 2009.

[3] S. Chua and T. H. Oh, "Green progress and prospect in Malaysia," J. Renewable and Sustainable Energy Reviews, vol. 15, pp. 2850-2861, 2011. 
[4] H. Radhi, "A systematic methodology for optimizing the energy performance of buildings in Bahrain,” J. Energy and Buildings, vol. 40, pp. 1297-1303, 2008.

[5] Z. Yu, C. M. Fung, F. Haghighat, E. Morofsky, and H. Yoshino, "A systematic procedure to study the influence of occupant behavior on building energy consumption,” J. Energy and Buildings, vol. 43, pp. 1409-1417, 2011.

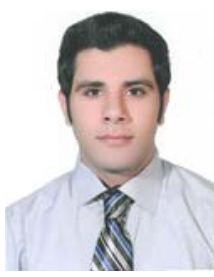

Mahmoud Shakouri Hassanabadi received his degree in architecture from Islamic Azad University, Iran in 2007 and started his master degree in construction management at University Teknologi Malaysia in 2010. His research interests are mainly building information modeling, energy analysis and also improving the performance of buildings with regard to sustainability standards.

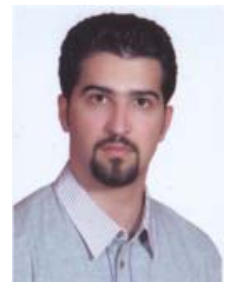

Seyed Saeed Banihashemi was born in Ardabil, Iran in 1985. He received his degree in architecture from Iran in 2008 and started his master degree in construction management at University Teknologi Malaysia in 2010. His research interests are mainly building information modeling, industrialized building system, energy analysis and also green building rating tools. Currently, as a part of his thesis research, he is trying to integrate industrialized building system with building information modeling by virtue of developing IFC algorithms for some prefabricated components. 